\title{
BUSINESS CONTINUITY MANAGEMENT AND PANDEMIC INFLUENZA
}

\section{Craig B Dalton}

Hunter New England Population Health

Hunter New England Health Service

\section{ABSTRACT}

Pandemic influenza planning presents challenges for both government and businesses. Effective cooperation and communication before and during a pandemic will help mitigate the major threats to societal function. The major challenges for government include communicating a realistic estimate of pandemic risk, managing community anxiety, communicating the need for rationing of vaccines and antiviral medications, setting standards for preparedness, and gaining the trust of essential service workers. For businesses the challenges are tailoring generic planning guides to local use, and making links with local and regional partners in pandemic planning.

Business continuity management, as defined by Standards Australia', 'provides the availability of processes and resources in order to ensure the continued achievement of critical objectives'. Until now, its most recent applications have been in information technology-the Y2K bug is an example-or in relation to the failure of physical infrastructure as a result of fire, flood, or earthquake. Throughout 2005, international and Australian health agencies warned of worst-case scenarios for pandemic influenza, with mass absenteeism that could cripple business and critical infrastructure and disrupt local and global supply chains. This paper focuses on the challenges faced by governments and the most essential private and public sector organisations in ensuring that appropriate business continuity management is implemented in our society during an influenza pandemic.

A range of estimates for staff absenteeism has been published in government pandemic plans to assist business preparation. These estimates are based upon 25 per cent of staff being absent at some time during the pandemic, but not for the entire pandemic period. The UK Influenza Contingency $\mathrm{Plan}^{2}$ uses modeling to predict that 25 per cent of employees will take between five and eight days off in three to four months of a pandemic. At least five to seven per cent would be absent in the peak week of impact, with the proportion rising to 15 per cent if the attack rate were to increase from 25 to 50 per cent. The Australian Health Management Plan for Pandemic Influenza predicts peak absenteeism rates of up to 50 per cent. ${ }^{3}$ Reasons for staff absence in a pandemic would include illness from the pandemic influenza strain; exclusion from work while suffering another respiratory tract infection mistaken for or treated on a cautionary basis as influenza; caring for ill children and relatives; caring for children if day-care and schools are closed by authorities; and fear of contracting pandemic influenza at work or while traveling to work.

Government agencies will not, on their own, be able to control the spread of pandemic influenza and maintain essential services. Measures that maintain societal function and reduce transmission of influenza in the community and at the workplace will reduce the peak incidence of the pandemic and help the health system to cope with the patient load.

\section{CHALLENGES FOR GOVERNMENT}

During a pandemic, government must play a leadership and coordinating role. While health departments are the lead agency for responding to pandemic influenza, there are many interagency committees active in planning at the state and national level. The lead agency supporting business continuity at the national level is the Australian Government Department of Industry, Tourism and Resources, and for NSW it is the Premiers Department. Both of these departments have published documents to support business continuity planning. ${ }^{4,5}$ The role of local government has not been extensively articulated; however, its links with emergency management networks and its role in maintaining routine services such as waste management and water supply will be important.

Getting continuity managers' attention and keeping it The Australian Minister of Health has provided a proactive example of awareness raising for a pandemic that has achieved international recognition. ${ }^{6}$ A major challenge will be balancing a sense of urgency with the acknowledgement that many organisations will take years to develop plans and will need to maintain them in perpetuity.

Black and Armstrong, in the first special issue of the Bulletin on avian and pandemic influenza, address the risk of a pandemic occurring and the attendant uncertainties of the timing and severity of its occurrence. ${ }^{7}$ To guard against the development of cynicism in non-health planning portfolios, short term predictions for the arrival of pandemic influenza should be avoided because planners and media commentators will become increasingly cynical, or even derisive, as 12-month or even five-year prediction intervals pass. Indeed, analyses of the genetic diversity of the H5N1 virus suggest it has been circulating in birds in China for almost 10 years without mutating to a pandemic virus. ${ }^{8}$

It is too late in the evolution of the debate to describe the risk of pandemic influenza as 'imminent'. Planners need to use standard risk matrices to gain senior executive support for prioritizing pandemic influenza by using a once-in-30-year risk for a 'milder' (1957 or 1968-like) pandemic scenario and a conservative once-in-100 year risk for a 'severe' (1918-like) pandemic scenario, while acknowledging that an event with an average recurrence level of 100 years has a 
10 per cent and 22 per cent probability of occurring in a 10 year and 25 year interval, respectively. ${ }^{9}$ Such risk estimates need to be qualified and reviewed as new information becomes available from epidemiological analyses, in vivo recombination experiments, and viral genetic analysis on H5N1 influenza virus (or future avian influenza strains).

\section{Preventing panic}

The second major challenge for government will be that of managing risk communication during a pandemic. Models of the economic impact of a pandemic find that the economic impact is not as sensitive to the mortality rate of the pandemic as it is to the behaviour of the community during a pandemic. An Australian Treasury paper predicts the decrease in shopping, leisure activities, travel and tourism will likely be mediated by the perceived risk of the pandemic rather than by the actual mortality rate. ${ }^{10}$ Decreases in demand for goods and services, and absenteeism, will combine to cause a slowing of the economy. It is possible that the next pandemic could have no greater excess mortality than our usual national seasonal influenza toll (about 3000 deaths per year for influenza and pneumonia combined $)^{11}$, but if distorted depictions emerge in the media with the announcement of the next pandemic, a SARS-like panic could develop, with significant societal impacts.

\section{Who will get the antivirals and vaccines?}

Many planning documents in Australia and overseas have flagged that 'essential service' or 'critical infrastructure' workers may be prioritised for antiviral medications or pandemic specific vaccines. A wide range of workers consider that they provide or support essential services and have an expectation that they should receive protective antiviral medication or vaccines. There is potential for unions and work group organisations to withdraw services during a pandemic pending receipt of antiviral medications. So far the Commonwealth Government has given no guarantee of supply to any group other than health care workers. There is an urgent need for government to clarify the reasons for prioritising front line health care workers for antiviral medications during a pandemic and to test the validity of this decision against the perceptions held among industry groups, business, workers and unions prior to a pandemic.

Health care workers should remain a priority because of the significant societal panic that will occur if influenza clinics and hospitals are abandoned in a pandemic and for the assumed society-wide benefits of preventing spread of pandemic influenza from health care workers into the wider community.

A post-exposure prophylaxis option, which requires that essential workers receive antiviral medication only after a suspected influenza exposure, may offer the health system greater flexibility in implementing prophylaxis while still providing reassurance to essential workers.

\section{Developing standards for business continuity plans}

While business, critical infrastructure and even health care organisations have been advised or directed to develop pandemic plans, the content, coverage and level of plans has rarely been specified or standardised and no independent standards exist for validating the readiness of organisations. Such standards would be useful not only in providing assurance to government and the community in general, but also in assisting businesses seeking to assess their supply chain threats in a pandemic.

\section{CHALLENGES FOR BUSINESS AND CRITICAL INFRASTRUCTURE}

Detailed frameworks and resources for business continuity management are available. ${ }^{1,12}$ Widespread absenteeism may result in both downstream and upstream supply chain failures and the situation may be complicated by increased demand for essential goods. The hospitality sector, on the other hand, may be affected by decreased demand during a pandemic. The following section focuses on some of the challenges faced by businesses in developing their plans.

\section{The legacy of a physical infrastructure and IT approach to continuity planning}

Many service sectors have a history of comprehensive business continuity planning for physical infrastructure or information technology failure. Businesses are very good at identifying their core business functions and identifying alternative service delivery options. To cite one example from the United States, FEDEX has five empty jets roaming the night skies waiting to be diverted to airports where scheduled flights are overbooked. ${ }^{13}$ Some businesses that rely heavily on information technology have well developed back-up networks that can operate from an alternative site or even a different continent.

While an information technology perspective provides a thorough grounding in business continuity management principles, the uncertainties associated with infectious diseases such as influenza pandemics may be overlooked. The standard advice from business continuity management plans, such as 'cross-training', telecommuting and infection control (including respiratory and cough hygiene), may be superficially reassuring in pandemic planning guides, but they are not a guarantee of appropriate readiness. There is a need to consolidate pandemic preparedness through effective internal communication and links with external partners, and to use risk assessment to adapt generic pandemic planning guides for local use.

\section{Communication and consultation with staff}

The fear and uncertainty that is associated with pandemic influenza make it vital that business organisations consult staff and unions about what infection control interventions will be implemented in the workplace. This consultation will need to include staff education, and also negotiation of infection control practices and protection measures to 
ensure maximum staff trust and satisfaction, and minimum absenteeism.

\section{Recognising that the risk of transmission in the workplace varies}

Many plans treat the workplace as a zone of homogenous risk; however, risk varies depending on crowding and travel and on the duration, frequency and closeness of contact with the public and other workers. Physically mapping risk areas may assist in planning and prioritising infection control interventions. Segregating groups of staff to decrease mixing could be more fully developed in some plans but special care must be used to ensure that groups at higher risk of infection are not stigmatised within an organisation. Few organisations have considered the protection of staff and their families as a package.

\section{Pandemic response as a local issue}

Many Australian corporate plans reviewed by the author see the World Health Organization and Australian Department of Health and Ageing as their primary source of information. Few have identified the website of their local health department as an information source, yet these sites will provide information such as whether the pandemic has been detected in their area; where their local influenza clinics are; what services are being offered by local hospitals, influenza clinics, general practitioners and other health workers; and if and when, and where, vaccines and antiviral medications will be available.

Businesses and government need to engage with local partners in different industrial and sector services to assess

\section{BOX 1}

\section{THE FOOD SUPPLY-A SPECIAL CASE}

When considering core societal functions the provision of health care, power, water, transport and food dominate. Of all of these, the food industry is the one with least government control and a special vulnerability that cannot be ignored. The production and delivery of food to supermarket shelves is a highly complex logistics-driven enterprise and only a few days supply is held at most supermarkets. Absenteeism at each link in the chain of food delivery from port services, heavy transport, warehousing, logistics, and supermarket stocking and sales threaten basic food supplies. Panic buying could empty shelves and looting could further delay resumption of services. Governments can recommend stockpiling of food and water to develop resilience in the community, but the greater challenge is to educate the community on how to effectively build and use a stockpile, and to provide basic food supplies across the country to ensure supply to the poor and immobile, and to people quarantined or ill. the feasibility of their planning assumptions where they interface with other sectors. A United States biotechnology company that published its pandemic plan in January 2006 advised that before visiting a shop for essential items workers should 'phone first to confirm availability of required items if possible'. ${ }^{14} \mathrm{~A}$ supermarket with pandemicrelated absenteeism is unlikely to cope with or endorse this recommendation. Rather than assuming supermarkets will provide a telephone enquiry service, it is far better to ask local supermarkets what their pandemic plans hold. Will there be curbside sale of essential items as flagged by one Florida-based supermarket? ${ }^{15}$ To minimise unrealistic recommendations, organisations should test their planning assumptions through cross-sectoral planning and scenario exploration with local mutual aid and emergency planning groups.

\section{CONCLUSION}

Challenges exist for government and business, but close cooperation is essential before and in a pandemic. Since many businesses can cope with a high level of absenteeism for a number of weeks or even months if they focus on their core functions, the major threats to societal function may be the flow-on effects of panic and uncorroborated planning assumptions. A comprehensive public communication strategy with pre-tested messages will be vital to minimising this threat to business and the community during an influenza pandemic.

\section{REFERENCES}

1. Standards Australia. Business continuity management HB 221: 2004. Available at www.standards.com.au.

2. United Kingdom Department of Health. Influenza contingency plan. October 2005. Available at www.dh.gov. uk/assetRoot/04/12/17/44/04121744.pdf. Accessed 21 April 2006.

3. Department of Health and Ageing. Australian health management plan for pandemic influenza. Department of Health and Ageing, 2006. Available at: www.health.gov. au/internet/wcms/Publishing.nsf/Content/ohp-pandemicahmppi.htm. Accessed 14 September 2006.

4. Department of Industry, Tourism and Resources. Being prepared for an influenza pandemic. Department of Industry, Tourism and Resources. Available at: www.industry.gov.au/ pandemicbusinesscontinuity. Accessed 14 September 2006.

5. NSW Government. NSW human influenza pandemic plan. Attachment B. Business continuity planning guide. Available at: www.emergency.nsw.gov.au/media/331.pdf. Accessed 14 September 2006

6. Lanard J, Sandman PM. Superb flu pandemic risk communication: A role model from Australia. Available at: www.psandman.com/col/abbott.htm. Accessed 21 April 2006.

7. Black M, Armstrong P. An introduction to avian and pandemic influenza. N SW Public Health Bull; 17(7-8): 99-103.

8. Chen H, Smith GJD, Li KS. Establishment of multiple sublineages of H5N1 influenza virus in Asia: Implications for pandemic control. Proc Natl Acad Sci U S A, 21 Feb 2006; 103(8): 2845-50. 
9. Granger K, Hayne M (editors). Natural hazards and the risks they pose to South-East Queensland. Canberra: Australian Geological Survey Organisation and the Department of Industry Science and Resources, 2001.

10. Kennedy S, Thomson J, Vujanovic P. 2006-01: A primer on the macroeconomic effects of an influenza pandemic. The Treasury, Australian Government. Available at: www.treasury. gov.au/contentitem.asp? NavId=049\&ContentID $=1069$. Accessed 6 December 2006.

11. Australian Institute of Health and Welfare. State and territories GRIM (General Record of Incidence of Mortality) Book - Pneumonia and influenza : Canberra: Australian Institute of Health and Welfare, 2005.
12. Business Continuity. Website with links to fluwiki sites. At: www.fluwikie.com/pmwiki.php? $\mathrm{n}=$ Consequences. WorkplaceContinuity. Accessed 21 April 2006.

13. Leonhardt D. FEDEX News from New York Times on the Web. At: www.fedex.com/us/about/news/nytoct $05 . h t m l$ ?link=4. Accessed 21 April 2006.

14. Microbix. Microbix pandemic plan. At: www.microbix. com/1502.html\#generalmeasures. Accessed 5 February 2006.

15. Jackson GW. Experts discuss bird flu response. Orlando Sentinel 6 April, 2006. Available at: www.orlandosentinel.com/ business/orl-birdflu0606apr06,0,5656766.story?coll=orlbusiness-headlines. Accessed 21 April 2006.

\section{THE EFFECTIVE USE OF THE MEDIA DURING AN INFECTIOUS DISEASE EMERGENCY}

\section{Wayne Geddes}

\section{Media and Communications}

NSW Department of Health

During an infectious disease emergency such as a pandemic of influenza, the media will play a critical role in disseminating public health information. Timely and accurate information can help facilitate coordination and cooperation within the community, reduce speculation and fear and maintain public confidence in the health system. The media can also actively assist public health responses by providing the public with advice on how to remain well and by telling people what they can do if they suspect they have the disease or have been in close contact with others who have it. In recognition of the important role of the media and other forms of communication during infectious disease emergencies, NSW Health is developing a communication strategy for infectious disease emergencies, based on recommendations from the 2004 NSW Taskforce on Severe Acute Respiratory Syndrome (chaired by Professor Ron Penny). ${ }^{1}$ With respect to public communication, the strategy will aim to ensure a constant flow of accurate information to the media, as an absence of information is likely to quickly result in speculation and misinformation.

While the strategy is still being developed, key features of the media component include:

- providing clear and simple messages based on advice from NSW Health and other appropriate agencies (for example, the Australian Government Department of Health and Ageing or, during the recovery phase of a pandemic, the NSW Department of Community Services)

- using a constant media face and identifying alternative spokespersons to engage the media when public health experts are not available. The chosen spokesperson(s) should be knowledgeable and authoritative and should provide consistent messages and facts

- providing media groups with telephone numbers for media information services so that they do not flood emergency services lines

- providing media statements, fact sheets and interviews as soon as possible after an outbreak is notified and then on a regular basis, each day

- utilising pre-existing resources and structures (for example, pre-existing websites and fact sheets) for the dissemination of public health information, and developing new resources where appropriate

- establishing a 1800 information line where recorded news releases are available and updated regularly

- establishing a dedicated website that provides timely information about the emergency

- using varied forms of media in addition to mainstream media (media releases and interviews) - for example, web-based information on the intranet and Internet

- encouraging the media to appropriately balance their responsibility for reporting news and events versus their role as providers of information during what will be a complex emergency

- recognising that media plans should cover different stages of an infectious disease emergency — recognising, for example, that media information is vital not only during the height of a pandemic, but also during the longer-term recovery phase when it can help ensure that patients and their families or relatives receive all available assistance and that people resume their normal lives as soon as possible after the outbreak.

\section{REFERENCES}

1. NSW Department of Health. Key recommendations of the NSW Taskforce on SARS (TSARS). Sydney: NSW Department of Health, 2004. 